\title{
Use of contraceptives among adolescents in Kintampo, Ghana: a cross-sectional study
}

\author{
This article was published in the following Dove Press journal: \\ Open Access Journal of Contraception \\ 2 May 2014 \\ Number of times this article has been viewed
}

\section{Ellen Abrafi Boamah \\ Kwaku Poku Asante \\ Emmanuel Mahama \\ Grace Manu \\ Emmanuel Kwesi Ayipah \\ Elisha Adeniji \\ Seth Owusu-Agyei}

Kintampo Health Research Center, Ghana Health Service, Kintampo, Ghana
Correspondence: Ellen Abrafi Boamah Kintampo Health Research Center, PO Box 200, Kintampo Brong

Ahafo Region, Ghana

Tel +233200527408

Email ellen.boamah@kintampo-hrc.org
Introduction: The use of contraceptives is essential in preventing unwanted pregnancies, unsafe abortions, and abortion-related complications that expose adolescents to health-related risks such as infertility and sometimes death.

Objective: To assess contraceptive use among adolescents as evidence to develop appropriate interventions for adolescent sexual health programs.

Methods: A cross-sectional survey using both quantitative and qualitative methods was conducted among 793 male and female adolescents (aged 15-19 years) in the Kintampo area of Ghana from October 2010-May 2011.

Results: Knowledge of at least one contraceptive method was high $(88.9 \%)$ among adolescents of both sexes (males $92.1 \%$ and females $86.6 \%$ ). Knowledge of male condoms was highest $(84.0 \%)$, and it was the most common contraceptive method used $(82.0 \%)$. The use of other methods such as pills $(7.9 \%)$, injection $(0.9 \%)$, and foam $(0.3 \%)$, amongst others, was low. About $22.9 \%$ of adolescents used contraceptives consistently. Among adolescents, consistent contraceptive use was significantly associated with discussions of contraceptive use between partners $(P<0.01)$. Adolescents who discussed contraceptive use before their first sexual encounter were more likely to use contraceptives consistently when compared to those who had never discussed contraceptive use (odds ratio $=0.06 ; 95 \%$ confidence interval: $0.02-0.17$; $P<0.01$ ). Among sexually active adolescents, $30.0 \%$ had experienced pregnancy, with $34.0 \%$ of pregnancies resulting in abortions. Pregnancy was high among adolescents who did not use contraceptives consistently, as compared to those who did $(6.4 \%$ versus $93.6 \% ; P<0.01)$. The most common source of contraceptives was the chemical seller's/pharmacy shop (62.1\%).

Conclusion: Though a high number of adolescents knew at least one contraceptive method, this knowledge did not influence them to consistently use contraceptives. Only a small percentage of the sexually active adolescents used a contraceptive method consistently. It is, therefore, recommended that an intervention for improving consistent contraceptive use among adolescents be pursued. The creation of adolescent-friendly centers for reproductive health services is highly proposed.

Keywords: contraceptive use, sexually active, contraceptive knowledge, sexual health

\section{Introduction}

Unprotected sexual intercourse makes adolescent females susceptible to unwanted pregnancies, which may lead to abortion, abortion-related complications, and other health and social problems such as infertility and dropping out from school. ${ }^{1-3}$ Unsafe sexual intercourse among adolescents is common. ${ }^{4}$ For instance, the 2008 Ghana Demographic Health Survey reports low levels of contraceptive use among adolescents $(24.0 \%$ among females and $39.0 \%$ among males $).{ }^{5}$ In another study conducted by Karim et $\mathrm{al}^{6}$ 
among unmarried adolescents in Ghana, 18.0\% and $27.0 \%$ of adolescent males and females, respectively, used condoms in their first sexual encounter. In the same study, consistent contraceptive use with their current partner was recorded among $24.0 \%$ and $20.0 \%$ of males and females, respectively. ${ }^{6}$ This sexual behavior may put adolescents (especially females) at a higher risk of unwanted pregnancy.

The use of contraceptives is influenced by numerous factors, which include knowledge of contraceptive methods and knowledge of their use, access to these methods, sociodemographic characteristics, and negotiation skills of the persons involved. ${ }^{6-9}$ Sexual intercourse in Ghana is seen as a preserve of only married adults due to religious, cultural, and social reasons. ${ }^{10}$ Issues regarding sex and contraception may, therefore, not be discussed at home, particularly amongst adults and young people. This scenario is likely to limit adolescent's access to information on issues related to sex and contraception. The next important source of information could be health facilities; however, adolescents feel embarrassed going to these facilities for information or services pertaining to sex and contraception ${ }^{3}$ due to the fact that they perceive that they will be met with an unwelcoming attitude at the facility given that service providers are the same adults that they live with, in the community.

To develop interventions that will help improve contraceptive use among adolescents, we conducted a crosssectional survey to determine the knowledge and predictors of consistent contraceptive use among adolescents in the middle belt of Ghana.

\section{Methods}

\section{Survey design}

The study was a cross-sectional survey using the Kintampo Health and Demographic Surveillance System (KHDSS) platform. ${ }^{11}$ The survey employed both qualitative and quantitative data collection techniques and was conducted between October 2010 and May 2011.

\section{Study area}

The study was conducted in two adjoining political administrative districts, the Kintampo North Municipality and Kintampo South Districts in central Ghana. The communities are mostly rural. In total, the area is almost $7,200 \mathrm{~km}^{2}$ and has a resident population of approximately $140,000 .{ }^{11}$ The population has a typical developing country structure, with $45 \%$ of the population younger than 15 years of age. ${ }^{11}$ Kintampo is multiethnic, but Mos and Akans form the majority of the tribes. ${ }^{11}$ About $75 \%$ of the individuals are Christians. ${ }^{11}$
The percentage of educated people in the study area in 2012, was low. Among the general population, approximately $49 \%$ of males and $55 \%$ of females were illiterate. However, these percentages were lower among adolescents (referred to here as $12-18$ years of age). Illiteracy levels were $22 \%$ among males and $25 \%$ among females. ${ }^{11}$ There is a high school dropout rate of more than $17.3 \%$ (14.8\% among males and $19.7 \%$ among females), with many adolescents abandoning school to support their parents in their daily activities such as farming and selling. ${ }^{12}$ About $63.8 \%$ of individuals in the population are crop farmers, laborers, or domestic workers. ${ }^{12}$

The study area has two district government hospitals, with one serving each district. The reproductive health services provided in the hospitals include family planning, sexually transmitted infection/human immunodeficiency virus (HIV)/acquired immunodeficiency syndrome prevention and management, and postabortion care. Adolescent reproductive health services in the area include health talks among identifiable groups such as secondary school students, job apprentices, and religious groupings. Adolescents have consistently contributed more than $10.0 \%$ of births that occur in Kintampo per year for the past 5 years. ${ }^{11}$ The maternal mortality ratio in Kintampo is $347 / 100,000,{ }^{13}$ and this is similar to the national ratio of $350 / 100,000$ live births. ${ }^{14}$

\section{Sampling procedure}

The survey was conducted among 793 male and female adolescents from 15-19 years of age. It was carried out in eight communities within the study area. A simple random sample of adolescents aged 15-19 years was generated with Stata version 11.0 (StataCorp LP, College Station, TX, USA), using the KHDSS database as a sampling frame. ${ }^{11}$ The KHDSS is a core component of the Kintampo Health Research Center. It is a health and demographic surveillance system that registers all households and residents in the Kintampo North Municipality, as well as in the south district. ${ }^{11}$ The names of residents, as well as their demographic data such as age, sex, and socioeconomic status have been collected by trained field staff since 2003 . The trained field staff members also register pregnancies, births, deaths, and migrations. The database is updated three times in a year. Updated data for the year 2011 were used as the sampling frame for this study. The list of selected adolescents that was generated contained the names and compound numbers of the prospective respondents. Trained fieldworkers were given this list and they approached the adolescents in their homes. Every available prospective respondent who consented to be part of the survey was enrolled and interviewed.

Adolescents were categorized into two age groups, early (15-17 years) and late (18-19 years) adolescence. 
Adolescents who participated in the focus group discussions were selected from the sample of quantitative respondents using simple random selection via Stata version 11. The quantitative data was collected first, followed by the qualitative data. Respondents for the qualitative study were selected from the adolescents who responded to the structured questionnaire interviews. This was done in order to further understand the responses obtained from the respondents in the quantitative results. The qualitative results have been used to interpret and support the quantitative results, where applicable.

Knowledge of contraceptives was assessed by adolescents' ability to name at least one contraceptive method. The consistent use of contraceptives was defined as the use of contraceptives for every sexual act; this was determined when adolescents answered "always" to the question, "How often do you use a contraceptive method during sex?"

\section{Sample size calculations}

The sample size for this study was calculated based on the prevalence of contraceptive use (23\%) by Karim et al. We assumed a worst acceptable prevalence of contraceptive use in our study area to be about $19 \%$. A sample size of 789 was calculated at $80 \%$ statistical power and $95 \%$ confidence to determine the true prevalence of contraceptive use in the study area.

\section{Instruments}

An eight-page structured questionnaire adapted from an adolescent reproductive health data collection tool by the United Nations Development Programme/United Nations Population Fund (UNFPA)/the World Health Organization $(\mathrm{WHO}) /$ World Bank ${ }^{15}$ was pretested in the study area and used for quantitative data collection. The data collected included the demographic characteristics of respondents, as well as the knowledge and use of contraceptives.

Another instrument on "In-depth interviews and Focus Group Discussions on Partner Selection, sexual behaviour and risk taking for adolescents" developed for the UNFPA/ WHO/World Bank ${ }^{15}$ was adapted and used for qualitative data collection. Seven separate focus group discussions were conducted, and each focus group comprised 8-12 participants. Discussions were held separately for males and females in the age groups of 15-17 years and 18-19 years. A research officer facilitated the discussion, while another took notes.

\section{Data management and analysis}

Completed questionnaires were checked for completeness and consistency, and sent to the Kintampo Health Research Center's (KHRC) (Kintampo, Ghana) computer laboratory for double entry into a password-protected database in Microsoft FoxPro version 9.0 (Microsoft Corporation, Redmond, WA, USA). Clean data were analyzed using Stata version 11.0.

Simple proportions and means were used to describe categorical and numerical data, respectively. Odds ratios and the Pearson's chi-squared tests were used to test for the strength of the association between the explanatory variables (sociodemographic and other possible predictor variables) and the outcome variables (knowledge of contraceptives and consistent contraceptive use). Univariate and multivariate logistic regression models were fitted to explore the predictors of consistent contraceptive use. The explanatory variables were age, age of first sexual encounter, level of education, religion, ethnicity, living arrangement, condition of sex (planned/ unexpected), knowledge of at least one contraceptive method, the ability to negotiate condom use, and discussion of contraception methods with a partner. The main outcomes variables of interest were knowledge of contraceptives (defined as the ability of an adolescent to mention at least one contraceptive method) and consistent contraceptive use (defined as the use of a contraceptive method for every sexual activity) among adolescents. The quantitative results have been presented as percentages and ratios.

In the analysis of the qualitative data, tape-recorded responses that were transcribed verbatim were put in a matrix, which represented the themes that were generated from the discussion. QSR NVivo qualitative analysis software (version 9.0; QSR International Pty Ltd, Doncaster, VIC, Australia) was used for data management. The qualitative data were presented as quotes to support the quantitative results, where applicable.

\section{Ethical considerations}

Scientific and ethical approvals for the study were obtained from the KHRC's Scientific Review Committee and the institution's Ethics Committee (FWA00011103), respectively. All participants individually provided their consent for their voluntary participation in the study. Parental consent and assent were obtained for minors. The consenting process involved explaining the purpose of the study, confidentiality procedures, risks and benefits, and the freedom to opt out of the study at any time. Consent was indicated by a signature or thumbprint, and a witness was used where a respondent was illiterate.

In order to guarantee the confidentiality of the study information, respondents were only identified with study codes. Completed survey forms were kept safely under lock and key within the KHRC, and they were accessible to only the named study investigators. 
Table I Sociodemographic characteristics of adolescents and their knowledge of at least one contraceptive method by demographic variable

\begin{tabular}{|c|c|c|c|c|}
\hline \multirow[t]{2}{*}{$\begin{array}{l}\text { Variable } \\
(n=793)\end{array}$} & \multirow{2}{*}{$\begin{array}{l}\text { Frequency } \\
\mathrm{n}(\%)\end{array}$} & \multicolumn{3}{|c|}{$\begin{array}{l}\text { Knowledge of at least one } \\
\text { contraceptive method }\end{array}$} \\
\hline & & $\begin{array}{l}\text { Yes } \\
\mathrm{n}(\%)\end{array}$ & $\begin{array}{l}\text { No } \\
\text { n (\%) }\end{array}$ & $P$-value \\
\hline \multicolumn{5}{|l|}{ Sex } \\
\hline Males & $342(43.1)$ & $315(92.1)$ & $27(7.9)$ & 0.01 \\
\hline Females & $45 \mathrm{I}(56.9)$ & $387(86.6)$ & $64(13.4)$ & \\
\hline \multicolumn{5}{|l|}{ Age group } \\
\hline 15-17 years & $49 \mid(61.9)$ & $419(85.3)$ & $72(14.7)$ & $<0.01$ \\
\hline $18-19$ years & $302(38.1)$ & $285(94.4)$ & $17(5.6)$ & \\
\hline \multicolumn{5}{|l|}{$\begin{array}{l}\text { Age at first sex } \\
(n=3 \mid 5)\end{array}$} \\
\hline II-14 years & $47(15.1)$ & $44(93.6)$ & $3(6.4)$ & $0.36 *$ \\
\hline $15-17$ years & $225(72.1)$ & $214(95.1)$ & II (4.9) & \\
\hline $18-19$ years & $40(12.8)$ & $40(100.0)$ & $0(00.0)$ & \\
\hline \multicolumn{5}{|l|}{ Formal education } \\
\hline Yes & 783 (98.7) & $697(89.0)$ & $9(90.0)$ & $0.92 *$ \\
\hline No & $10(1.3)$ & $86(11.0)$ & $I(10.0)$ & \\
\hline \multicolumn{5}{|l|}{ Educational level } \\
\hline None & $10(1.2)$ & $9(90.1)$ & I (9.9) & $<0.01 *$ \\
\hline Primary school/JHS & $668(84.3)$ & $58 \mid(87.5)$ & $29(21.3)$ & \\
\hline SHS and above & $115(14.5)$ & $112(97.4)$ & $2(6.9)$ & \\
\hline \multicolumn{5}{|l|}{ Religion } \\
\hline Christianity & $628(79.2)$ & 527 (9I.I) & $56(8.9)$ & $<0.01 *$ \\
\hline Islam & $136(17.2)$ & $107(78.7)$ & $29(21.3)$ & \\
\hline Traditional/other & $29(3.6)$ & $27(93.1)$ & $2(6.9)$ & \\
\hline \multicolumn{5}{|l|}{ Ethnicity } \\
\hline Akan & $303(38.2)$ & $285(94.1)$ & I8 (5.94) & $<0.01 *$ \\
\hline Mo & I73 (2I.8) & $155(89.6)$ & $18(10.4)$ & \\
\hline Dagarti/Frafra & $|3|(2 \mid .8)$ & $117(89.3)$ & 14 (10.7) & \\
\hline Sisala/Wala & $77(9.7)$ & $56(72.7)$ & $21(27.3)$ & \\
\hline Gonja/Dagomba & $43(9.7)$ & $36(83.7)$ & $7(16.3)$ & \\
\hline Konkomba/Baasare & $25(3.2)$ & $20(80.0)$ & $5(20.0)$ & \\
\hline Other & $4 \mid(3.2)$ & $37(90.2)$ & $4(9.8)$ & \\
\hline \multicolumn{5}{|l|}{ Living arrangements } \\
\hline Both parents & $452(57)$ & $398(88.1)$ & 54 (11.9) & $0.57^{*}$ \\
\hline One parent & $193(24.3)$ & $175(90.7)$ & $18(9.3)$ & \\
\hline $\begin{array}{l}\text { Other relative/ } \\
\text { guardian }\end{array}$ & $113(14.3)$ & $100(88.5)$ & $13(11.5)$ & \\
\hline Other & $35(4.4)$ & $33(94.3)$ & $2(5.7)$ & \\
\hline
\end{tabular}

Notes: *Fisher's exact test was used for these $P$-value calculations. Age at first sex: three respondents did not know their age at first sex, and so they were excluded from the analysis.

Abbreviations: n, number; JHS, junior high school; SHS, senior high school.

\section{Results}

\section{Basic demographic characteristics of respondents}

A total of 793 adolescents ( $43.0 \%$ males and $57.0 \%$ females) participated in the survey (Table 1) with $100 \%$ response rates. The mean age of the respondents was 16.9 years (standard deviation $=1.4$ ). Only $0.8 \%$ of the adolescents were married. The majority of adolescents were Christians (79.2\%). Akans formed the largest (79.2\%) ethnic group of adolescents interviewed. Fifty-seven percent of the participants were living with both parents; the rest either lived with one parent $(24.3 \%)$, other relatives/a guardian $(14.3 \%)$, or had other living arrangements (4.4\%). Ninety-seven percent of the study participants have had some level of formal education (Table 1).

\section{Knowledge of contraceptives among adolescents by sociodemographic characteristics}

Approximately 89\% (705/793) of the adolescents interviewed knew about at least one contraceptive method; most of them $(84.0 \%)$ mentioned the male condom. With respect to specific contraceptive types, a spontaneous response to knowledge about condoms was highest (85.8\%; 681/793) among both males and females. Apart from condoms, a spontaneous response to knowledge of other modern contraceptive methods, such as the pill $(31.4 \% ; 249 / 793)$, injection (25.5\%; 203/793), and emergency contraceptives (5.6\%; 45/793), among others, was relatively lower. Knowledge of at least one contraceptive method was highest among males when compared to females $(92.1 \%$ versus $86.6 \%$, respectively; $P=0.01$ ) (Table 1). Knowledge of at least one contraceptive method was lower among 15-17-year-old adolescents when compared to $18-19$-year-old adolescents ( $85.3 \%$ versus 94.4\%, respectively; $P<0.01$ ) (Table 1). Knowledge of at least one contraceptive method was high among adolescents who had formal education (beginning at the senior high school levels and beyond) (97.4\%) compared to adolescents who had only primary/junior high (87.5\%) education and adolescents who had no formal education (90\%) $(P=0.01)$ (Table 1). Knowledge of at least one contraceptive method was high (>80\%) among all ethnic groups of adolescents (Table 1).

Table 2 Contraceptive methods often used by adolescents who have ever used a contraceptive method

\begin{tabular}{lll}
\hline Method & N (2II) & $\%$ \\
\hline Condom & 173 & 82.0 \\
Pill & 25 & 11.8 \\
Emergency contraceptive pill & 4 & 1.9 \\
Injection & 3 & 1.4 \\
Foam & $\mathrm{I}$ & 0.5 \\
Withdrawal & 4 & 1.9 \\
Safe period & $\mathrm{I}$ & 0.5 \\
\hline
\end{tabular}

Abbreviation: $\mathrm{N}$, number. 


\section{Contraceptive use among adolescents}

Sixty-seven percent (211/315) of sexually active adolescents had ever used contraceptives. Contraceptive use during the first sexual encounter was $55.2 \%$ (174/315). About $22.9 \%$ (72/315) used contraceptives consistently, while $44.1 \%$ (139/315) used contraceptives sometimes. Some of the methods used were condoms, the pill, and foam, among others (Table 2). Thirty-three percent (104/315) of adolescents had never used any method to prevent pregnancy. Adolescents who consistently used a contraceptive method were significantly less likely to get pregnant or impregnate someone compared to those who did not use contraceptives consistently ( $6.4 \%$ versus $93.6 \% ; P<0.01)$.

\section{Sources of contraceptives among adolescents}

Adolescents who had ever used any form of contraception $(211 / 315)$ were asked where they accessed these contraceptives. The majority of adolescents $(62.1 \% ; 131 / 211)$ reported accessing contraceptives from the pharmacy and the chemical seller's shops (Figure 1). Very few adolescents (3.6\% of males and $4.9 \%$ of females) accessed their contraceptives from health care facilities (Figure 1).

\section{Ability to discuss contraceptive use among sexually active adolescents}

Sexually active adolescents were interviewed about their ability to discuss contraceptives with their partners. Forty-two percent (134/315) had never discussed contraception with their partners. Thirty-two percent (67/211) of adolescents who had ever used a contraceptive method took the decision to use the contraceptives themselves. About $79.0 \%$ (250/315) of all sexually active adolescents could ask their partner to use a condom every time they had sex. Adolescents could negotiate condom use through persuasion or through the "hard way", as demonstrated in the focus group discussions in the subsequent sections.

\section{Negotiating condom use through persuasion}

The lady will say that you know I am young and still in school and am likely to get pregnant if we have sex without a condom so I would want us to use a condom. If you say that, the man will agree. (18-year-old female)

The girl can tell the man that, if only you love me, then you should use a condom because I can become pregnant. If you say that, the man will use a condom. (16-year-old female)

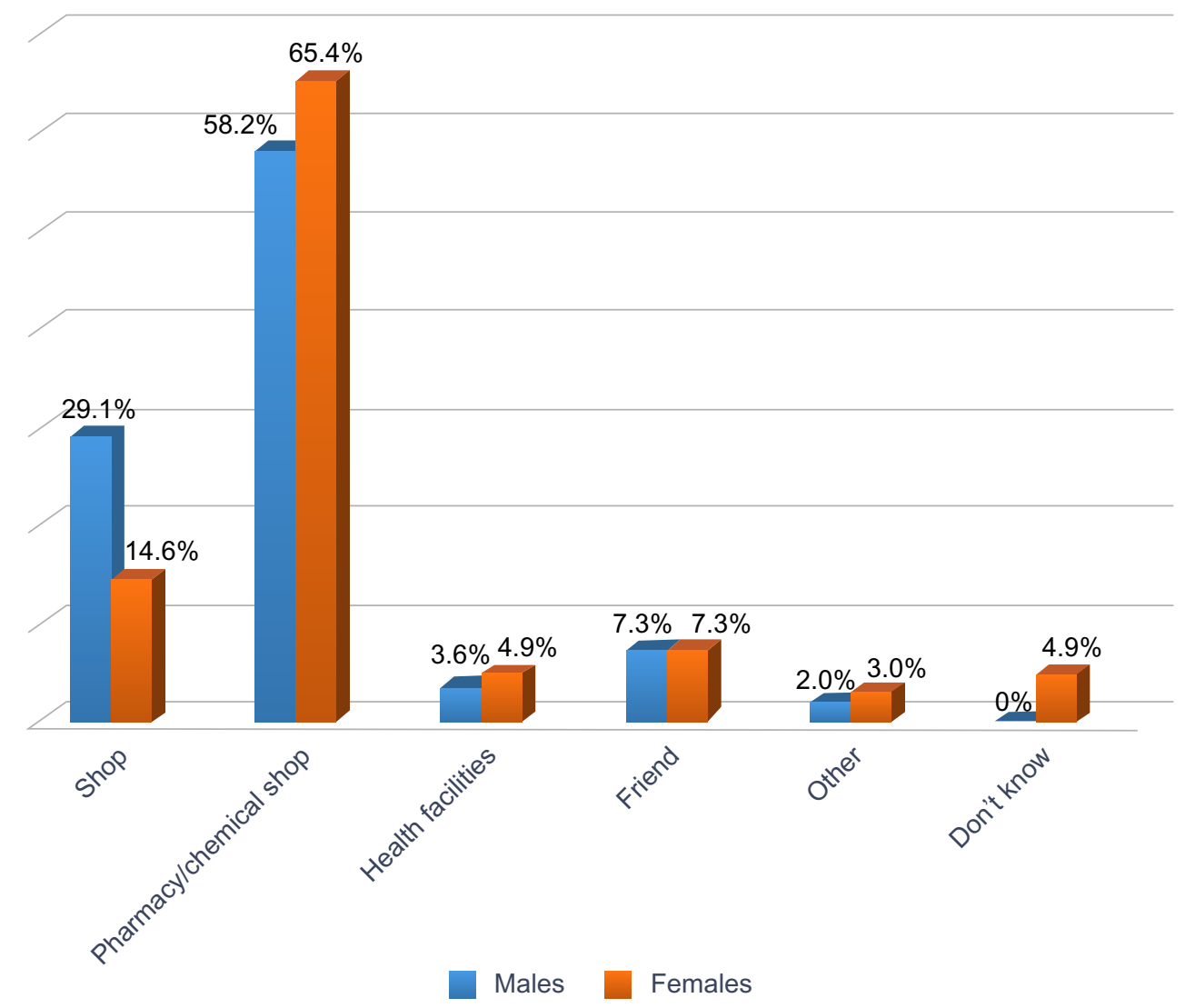

Figure I Proportion of male and female adolescents in the Kintampo area, as related to the source of contraceptives used (20I I). 
Table 3 Univariate and multivariate logistic regression analysis of the predictors of consistent contraceptive use among adolescents

\begin{tabular}{|c|c|c|c|c|c|c|c|c|}
\hline \multirow[t]{3}{*}{ Variables } & \multicolumn{2}{|c|}{$\begin{array}{l}\text { Consistent } \\
\text { contraceptive use }\end{array}$} & \multirow[t]{3}{*}{$\begin{array}{l}\text { Crude } \\
\text { OR }\end{array}$} & \multirow[t]{3}{*}{$95 \% \mathrm{Cl}$} & \multirow[t]{3}{*}{$P$-value } & \multirow[t]{3}{*}{$\begin{array}{l}\text { Adjusted } \\
\text { OR }\end{array}$} & \multirow[t]{3}{*}{$95 \% \mathrm{Cl}$} & \multirow[t]{3}{*}{$P$-value } \\
\hline & Yes & No & & & & & & \\
\hline & $\mathbf{N}(\%)$ & $\mathbf{N}(\%)$ & & & & & & \\
\hline \multicolumn{9}{|l|}{ Age } \\
\hline $15-17$ years & $33(24.4)$ & $102(75.6)$ & I & & & & & \\
\hline $18-19$ years & $40(22.2)$ & I 40 (77.8) & 0.88 & $0.52-1.49$ & 0.64 & - & - & - \\
\hline \multicolumn{9}{|l|}{ Age at first sex } \\
\hline II-14 years & $8(17.0)$ & 39 (82.9) & I & & & I & & \\
\hline $15-17$ years & $48(21.3)$ & I 77 (78.7) & 1.32 & $0.57-3.01$ & $0.01 *$ & 1.13 & $0.46-2.79$ & 0.08 \\
\hline $18-19$ years & $17(42.5)$ & $23(57.5)$ & 3.60 & $1.34-9.65$ & & 2.66 & $0.90-7.87$ & \\
\hline \multicolumn{9}{|l|}{ Education } \\
\hline Primary/JHS & $56(23.5)$ & I $82(76.5)$ & 1 & & & & & \\
\hline SHS and above & $17(24.3)$ & $53(75.7)$ & 1.04 & $0.55-1.94$ & 0.89 & - & - & - \\
\hline \multicolumn{9}{|l|}{ Religion } \\
\hline Christianity & $64(24.3)$ & 199 (75.7) & I & & & & & \\
\hline Muslim & $9(19.1)$ & $38(80.9)$ & 0.73 & $0.33-1.60$ & 0.44 & - & - & - \\
\hline \multicolumn{9}{|l|}{ Ethnicity } \\
\hline Akan & $46(27.5)$ & I2I (72.5) & I & & & & & \\
\hline Mo & $4(11.1)$ & $32(88.9)$ & 0.32 & $0.11-0.98$ & & & & \\
\hline Dagarti/Frafra & $9(18.0)$ & $41(82.0)$ & 0.57 & $0.26-1.28$ & & & & \\
\hline Other & $14(22.6)$ & $48(77.4)$ & 0.76 & $0.38-1.50$ & $0.11 *$ & - & - & - \\
\hline \multicolumn{9}{|l|}{ Residence } \\
\hline Both parents & $33(23.2)$ & $109(76.8)$ & 1 & & & & & \\
\hline One parent & $23(22.5)$ & 79 (77.5) & 0.96 & $0.52-1.76$ & & & & \\
\hline Other guardian & $13(25.5)$ & $38(74.5)$ & 1.12 & $0.53-2.36$ & & & & \\
\hline Other & $4(20.0)$ & $16(80.0)$ & 0.82 & $0.25-2.64$ & $0.96 *$ & - & - & - \\
\hline \multicolumn{9}{|l|}{ Condition of sex } \\
\hline Planned & $62(22.5)$ & $214(77.5)$ & 1 & & & & & \\
\hline Unexpected & II (28.2) & $28(71.8)$ & 1.35 & $0.63-2.87$ & 0.42 & - & - & - \\
\hline \multicolumn{9}{|c|}{ Contraceptive knowledge } \\
\hline Yes & $229(76.1)$ & $13(92.9)$ & $\mathrm{I}$ & & & & & \\
\hline No & $72(23.9)$ & I (7.I) & 4.08 & $0.52-31.78$ & 0.10 & - & - & - \\
\hline \multicolumn{9}{|l|}{ Negotiate condom use } \\
\hline Able to negotiate & $4(25.6)$ & $186(74.4)$ & I & & & 1 & - & - \\
\hline Unable to negotiate & $9(13.8)$ & $56(86.2)$ & 0.46 & $0.21-0.99$ & $0.04 * *$ & 0.70 & $0.30-1.64$ & 0.41 \\
\hline \multicolumn{9}{|l|}{ Discussed contraceptives } \\
\hline Before first sex & $60(38.5)$ & $96(61.5)$ & I & & & I & - & - \\
\hline After first sex & $8(32.0)$ & $17(68.0)$ & 0.75 & $0.30-1.86$ & & 0.73 & $0.27-1.92$ & - \\
\hline Never discussed & $5(3.7)$ & $129(96.3)$ & 0.10 & $0.02-0.16$ & $<0.01$ & 0.06 & $0.02-0.17$ & $<0.01$ \\
\hline
\end{tabular}

Notes: *P-value of likelihood ratio. **Fisher's exact test was used for the $P$-value calculation. Age at first sex: three respondents did not know their age at first sex, and so they were excluded from the analysis. Contraceptive knowledge referred to knowledge of at least one contraceptive method.

Abbreviations: $\mathrm{OR}$, odds ratio; $\mathrm{Cl}$, confidence interval; $\mathrm{N}$, number; JHS, junior high school; SHS, senior high school.

Negotiation for condom use through the "hard way"

The female can also use the hard way. She will say that if you do not use a condom then I will not allow you to have sex with me. Like the advert that says, "If it is not on, it is not in." So if you say that and the man really want to have sex with you, he will use the condom. (17-year-old male)

\section{Predictors of consistent contraceptive use among adolescents}

The associations between adolescents' demographic variables with some predictor variables and consistent contraceptive use were explored using univariate and multivariate regression analyses.

Age was not significantly associated with consistent contraceptive use $(P=0.64)$. However, age at first sex was significantly associated with consistent contraceptive use $(P=0.01)$. There was an increasing trend in terms of the odds of consistent contraceptive use with an increase in age at first sex: adolescents who began having sex from ages 18-19 years had a more than threefold chance of engaging in consistent contraceptive use when compared to adolescents who started having sex at ages 11-14 years 
(odds ratio $[\mathrm{OR}]=3.60 ; 95 \%$ confidence interval $[\mathrm{CI}]$ : 1.34-9.65; $P=0.01$ ) (Table 3).

Adolescents' residential status was not significantly associated with consistent contraceptive use $(P=0.96)$ (Table 3$)$. Knowledge of at least one contraceptive method was not significantly associated with consistent contraceptive use $(P=0.10)$ (Table 3).

Consistent contraceptive use among adolescents was significantly associated with the discussion of contraceptive use with partners $(P<0.01)$. Adolescents who discussed contraceptive use before their first sexual encounter were more likely to use contraceptives consistently when compared to those who had never discussed contraceptives ( $\mathrm{OR}=0.06$; 95\% CI: 0.02-0.17; $P<0.01$ ) (Table 3).

\section{Consequences of adolescents not using contraceptives}

Thirty percent (94/315) of sexually active adolescents had experienced pregnancy in their relationships during the survey. Forty-three percent (40/94) had delivered their babies, 4.0\% (4/94) had stillbirths, 34.0\% (32/94) had abortions, and $19.0 \%$ (18/94) were still pregnant.

\section{Discussion}

This survey sought to document adolescents' knowledge surrounding contraceptives, as well as their consistent contraceptive use. The conduct of the survey was informed by the high levels of adolescent pregnancies in the study area. ${ }^{11}$ The discussion focuses on adolescents' knowledge of contraceptives, their use of contraceptives, and the existing gap between adolescents' knowledge and use of contraceptives, including other interesting findings.

\section{Knowledge of contraceptives}

The common sources of information regarding contraceptives in Ghana are television and radio. ${ }^{16}$ Knowledge of at least one contraceptive method among adolescents in this survey was very high, and this was mostly knowledge of male condoms. Knowledge of contraceptive types was, however, not encouraging. The national survey of adolescents in Ghana conducted by Awusabo-Asare et $\mathrm{al},{ }^{10}$ as well as other studies, showed similar results. ${ }^{16,17}$ The low level of knowledge regarding contraceptive methods other than male condoms seems to be a general problem among adolescents in the country. ${ }^{10,16,17}$ The finding from this study is, however, not very surprising because, at the peak of the HIV epidemic, all programs focusing on HIV prevention revolved around consistent condom use if one could not abstain from sex or be faithful to a partner. ${ }^{18}$ Advertisements promote condom use on all media platforms; hence, there is a broadening awareness of condoms. ${ }^{18}$ Another reason for the high level of knowledge regarding condoms could be due to the fact that condoms are the most appropriate contraceptive methods used among unmarried adolescents. Given its dual capacity to prevent sexually transmitted infections and unwanted pregnancy, condoms are mostly recommended to adolescents. ${ }^{19}$

Knowledge of at least one contraceptive method varied across groups of adolescents; knowledge among males was higher than among females. The early adolescents had significantly lower levels of knowledge of at least one contraceptive method, as compared to the late adolescents. This implies that intervention programs that are implemented to improve adolescents' knowledge of contraceptives should be intensified.

\section{Use of contraceptives}

Use of contraceptives was relatively low among the adolescents studied, as was found in several other studies conducted among adolescents. ${ }^{5,6,20,21}$ Although some adolescents had reported ever using a contraceptive method in this survey, consistent contraceptive use was very low. Several factors such as level of knowledge, sex, age, cost, and contraceptive availability, among others, might account for this. Even though contraceptive use was low, there was a disproportionate use of male condoms when compared to other contraceptive methods. Possible reasons for this could include the fact that adolescents have easy access to condoms. Condoms are available almost everywhere, ranging from the chemical seller's shops to restaurants. Adolescents do not have to go to a health facility to get condoms, which is in contrast to the other methods. Going to the health facility for reproductive health services could be a Herculean task for adolescents. Adolescents are most likely to be scorned, rebuked, ridiculed, labeled, or sometimes driven away by service providers at health facilities. ${ }^{3}$ This unwelcoming attitude by service providers could explain why only a few adolescents in this survey have reported health facilities as their source of acquisition of contraceptives. This may limit an adolescent's opportunity to use other contraceptive options that are mostly available at health facilities and not in chemical shops and other places.

Another reason for the disproportionate condom use might be that male condoms are cheaper, as compared to the other contraceptive methods. ${ }^{22}$

The fact that adolescents are more knowledgeable about condoms, as compared to the other methods, may contribute to why condoms are mostly used. 


\section{Gap between knowledge and use of contraceptives}

Though knowledge of at least one contraceptive method was high among adolescents, consistent contraceptive use was rather low. This is possibly because adolescents may be lacking in the depth of their knowledge of various contraceptive methods. Misconceptions about various contraceptive methods may influence contraceptive use. ${ }^{2}$

Another important determinant of the gap between knowledge of contraceptives and consistent contraceptive use could be sex. Adolescents may know about contraceptives, but their sex could hinder the use of contraceptives. In this survey, consistent contraceptive use was higher in males when compared to females. The female sex seemed to be a barrier in accessing contraceptives. The results from Rondini and Krugu's study ${ }^{21}$ conducted in the upper East region of Ghana showed that a female could not buy a condom because she would be perceived as a "bad" girl. Similar studies have indicated that males will reject a condom from a female partner. ${ }^{21-24}$

The inability to discuss contraception with a partner and to insist on condom may create a gap between contraceptive knowledge and use. ${ }^{25}$ Findings from this survey indicate that one's ability to discuss contraception and to negotiate condom use with one's partner positively influenced consistent contraceptive use. Therefore, in addition to knowledge on contraceptives, adolescent females, in particular, should be empowered to be able to discuss and negotiate contraceptive use.

Another reason for the gap between the knowledge of contraceptives and consistent contraceptive use might be age. Consistent contraceptive use among the early adolescents was higher than among the late adolescents. This might be because older adolescents may no longer perceive themselves as being vulnerable, or they may be maturing into marriage and no longer see the need for contraception. However, these results contradict the findings from other studies, where contraceptive use increased with age..$^{23,26}$

\section{Other findings}

Inconsistent contraceptive use among adolescents may explain why some adolescents in this survey are now teen parents, and now face untoward social consequences. Other adolescents aborted their pregnancies and may face unpredictable fertility-related difficulties and other health challenges if these were unsafe abortions. , $^{21}$

There is a high possibility that the adolescents who have given birth, and those who are still pregnant, will not go back to school. ${ }^{2}$ These outcomes are likely to impede the adolescent's well-being and that of his or her children economically, physically, socially, and emotionally, and these outcomes could be extended to the adolescents' families, leading to debilitating effects on the country as a whole.

\section{Conclusion}

This survey has demonstrated that adolescents have appreciable knowledge of at least one contraceptive method, and this knowledge is mostly associated with condoms. However, this level of knowledge has not been translated into practice for several reasons such as lack of negotiation skills, age, sex, and level of education amongst others.

\section{Recommendations}

It is prudent to help adolescents know about other methods of contraception, such as the pill and injection, apart from the male condom. This would give adolescents a variety of methods to choose from - especially for females, who may not be able to insist on condom use.

The lessons from this study call for the creation of youth-friendly centers where adolescents can confidently and conveniently go to seek contraceptive services, counseling regarding sex, sexuality, and pregnancy.

In-depth and tailored education regarding contraception should be provided to adolescents as part of regular health information. This service should not only be limited to adolescents who attend antenatal clinics, as is usually the case. ${ }^{18}$ This will help adolescents who are not pregnant, as well as the males who do not go to antenatal clinics, to be well informed about the choices they can make regarding contraception.

Finally, there is an urgent need to undertake programs that would empower adolescents, especially females, to become assertive in negotiating condom use every time they want to have sex and do not want to use other contraceptive methods. The district health management teams could include this in their school health programs and occasional health talks to identified youth groups. Continuous advocacy should be available to adolescents who are not abstaining from sex, so they can continuously use contraceptives as a way of protecting themselves from unwanted pregnancies.

All these interventions, if put in place, will go a long way to improve and sustain contraceptive use among adolescents in the Kintampo area.

\section{Study limitation}

This study addressed sensitive subject matter where adolescents were asked intimate questions about their private sexual lives. The sensitive nature of the questions had the potential of making adolescents uncomfortable in giving their responses. The moral expectations of society concerning sexuality, especially among adolescents, could influence adolescents' 
ability to answer the questions in morally acceptable ways. This situation had the possibility to bias their responses; however, a high level of confidentiality was maintained during the interviews to ensure that the adolescents were at ease in giving their responses. Questions were administered by trained fieldworkers who were within similar age bands as the adolescents in order to help the respondents feel comfortable to talk.

\section{Acknowledgments}

The authors are extremely grateful to the director and the management team of the Kintampo Health Research Center, as well as to the Advisory Board. They are also thankful to the staff of the KHRC, who contributed in diverse ways to the success of the survey and this write-up. We especially thank Dr Alexander Ansah Manu and Dr Frank Baiden for reviewing the manuscript.

Our special thanks go to the respondents, without whom this work would have been impossible.

\section{Disclosure}

The authors report no conflicts of interest in this work.

\section{References}

1. Yen S, Martin S. Contraception for adolescents. Pediatr Ann. 2013;42(2): $21-25$.

2. Okereke CI. Unmet reproductive health needs and health-seeking behaviour of adolescents in Owerri, Nigeria. Afr J Reprod Health 2010;14(1):43-54.

3. Awusabo-Asare K, Bankole A, Kumi-Kyereme A. Views of Adults on Adolescent Sexual and Reproductive Health: Qualitative Evidence from Ghana. Occasional Report No 34. New York, NY: Guttmacher Institute; 2008.

4. Eaton DK, Kann L, Kinchen S, et al. Youth risk behaviour surveillanceUnited States, 2011. MMWR. 2012;61(4):1-162.

5. Ghana Statistical Service; Ghana Health Service; ICF Macro. Ghana Demographic and Health Survey 2008. Accra, Ghana: Ghana Statistical Health Service; 2009.

6. Karim AM, Magnani RJ, Morgan GT, Bond CK. Reproductive health risk and protective factors among unmarried youth in Ghana. Int Fam Plan Perspect. 2003;29(1):14-24.

7. Mehra D, Agardh A, Petterson KO, Östergren PO. Non-use of contraception: determinants among Ugandan university students. Glob Health Action. 2012;5:18599.

8. Slap GB, Lot L, Huang B, Daniyam CA, Zink TM, Succop PA. Sexual behaviour of adolescents in Nigeria: cross sectional survey of secondary school students. BMJ. 2003;326(7379):15.

9. Adetunji J. Condom use in marital and nonmarital relationships in Zimbabwe. Int Fam Plan Perspect. 2000;26(4):196-200.

Open Access Journal of Contraception

\section{Publish your work in this journal}

Open Access Journal of Contraception is an international, peerreviewed, open access, online journal, publishing original research, reports, reviews and commentaries on all areas of contraception. In addition to clinical research, demographics and health-related aspects, the journal welcomes new findings in animal and preclinical studies
10. Awusabo-Asare K, Biddlecom A, Kumi-Kyereme A, Patterson K. Adolescent Sexual and Reproductive Health in Ghana: Results from the 2004 National Survey of Adolescents. Occasional Report No 22. New York, NY: Guttmacher Institute; 2006.

11. Owusu-Agyei S, Nettey OE, Zandoh C, et al. Demographic patterns and trends in Central Ghana: baseline indicators from the Kintampo Health and Demographic Surveillance System. Glob Health Action. 2012;5:1-11.

12. Ministry of Local Government and Rural Development [webpage on the Internet]. Educational sector. Accra, Ghana: Ministry of Local Government and Rural Development; 2006. Available from: http://www.ghanadistricts. $\mathrm{com} /$ districts $/ ? \mathrm{r}=10 \& \_=37 \& \mathrm{sa}=1527$. Accessed January 1, 2014.

13. Kirkwood BR, Hurt L, Amenga-Etego S, et al; Obaapa VitA Trial Team. Effect of vitamin A supplementation in women of reproductive age on maternal survival in Ghana (ObaapaVitA): a cluster-randomised, placebo-controlled trial. Lancet. 2010;375(9726):1640-1649.

14. World Health Organization; UNICEF; UNFPA; The World Bank. Trends in Maternal Mortality: 1990 to 2010. WHO, UNICEF, UNFPA and The World Bank Estimates. Geneva, Switzerland: World Health Organization; UNICEF, UNFPA, The World Bank; 2012.

15. Cleland J, Ingham R, Stone N. Asking Young People about Sexual and Reproductive Behaviours: Illustrative Core Instruments. Occasional Report No 13. Geneva, Switzerland: World Health Organization; 2001.

16. Awusabo-Asare K, Abane AM, Kumi-Kyereme A. Adolescent Sexual and Reproductive Health in Research Evidence. New York, NY: Guttmacher Institute; 2004.

17. Bankole A, Biddlecom A, Guiella G, Singh S, Zulu E. Sexual behavior, knowledge and information sources of very young adolescents in four subSaharan African countries. Afr J Reprod Health. 2007;11(3):28-43.

18. Awusabo-Asare K, Abane AM, Kumi-Kyereme A. Adolescent Sexual and Reproductive Health in Ghana: A Synthesis of Research Evidence. Available from http://www.guttmacher.org/pubs/or_no13.pdf. Accessed March 20, 2014.

19. O'Leary A. Are Dual-Method Messages undermining STI/HIV Prevention? Infection Disease in Obstetrics and Gynecology. 2011; Article ID 691210. 7 Pages.

20. Biddlecom AE, Munthali A, Singh S, Woog V. Adolescents' views of and preferences for sexual and reproductive health services in Burkina Faso, Ghana, Malawi and Uganda. Afr J Reprod Health. 2007;11(3):99-110.

21. Rondini S, Krugu JK. Knowledge, attitude and practices study on reproductive health among secondary school students in Bolgatanga, upper east region, Ghana. Afr J Reprod Health. 2009;13(4):51-66.

22. Planned Parenthood of Southeastern Virginia. The 10 Most Effective Types of Contraception. Virginia Beach, VA: Planned Parenthood of Southeastern Virginia. Available from: http://www.ppsev.org/media/documents/ Top10BestFormsofContraception.pdf. Accessed March 18, 2014

23. MacPhail C, Campbell C. 'I think condoms are good but, aai, I hate those things': condom use among adolescents and young people in a Southern African township. Soc Sci Med. 2001;52(11):1613-1627.

24. Varga CA. Sexual decision-making and negotiation in the midst of AIDS: youth in KwaZulu-Natal, South Africa. Health Transit Rev. 1997; 7(Suppl 3):45-67.

25. Ogunjuyigbe PO, Ojofeitimi EO, Liasu A. Spousal communication, changes in partner attitude, and contraceptive use among the Yorubas of southwest Nigeria. Indian J Community Med. 2009;34(2):112-116.

26. Glover EK, Bannerman A, Pence BW, et al. Sexual health experiences of adolescents in three Ghanaian towns. Int Fam Plan Perspect. 2003;29(1):32-40.

\section{Dovepress}

relating to understanding the biological mechanisms and practical development of new contraceptive agents. The manuscript management system is completely online and includes a very quick and fair peer-review system. Visit http://www.dovepress.com/testimonials.php to read real quotes from published authors. 